\title{
Gerenciamento de resultados contábeis em oferta pública de ações
}

\author{
Earnings management in a public offering
}

Gestión de los ingresos por las empresas en la oferta pública de acciones

\author{
Sylvia Rejane Magalhães Domingos \\ Mestra em Administração e Controladoria pela Universidade Federal do Ceará \\ Doutoranda em Administração e Controladoria pela Universidade Federal do Ceará \\ Endereço: Rua Padre Sá Leitão, n 337 - Bairro Jóquei Clube \\ CEP: 60.521-032 - Fortaleza/Ceará - Brasil \\ E-mail: sylvia_rejane@hotmail.com \\ Telefone: (85) 99676-5515

\section{Vera Maria Rodrigues Ponte} \\ Doutora em Contabilidade pela Universidade de São Paulo \\ Professora do Departamento de Contabilidade da Universidade Federal do Ceará \\ Endereço: Avenida Rui Barbosa, $n^{\circ} 255$ - Apto 1700 - Torre Vinícius de Moraes - Bairro Meireles \\ CEP: 60.115-220 - Fortaleza/Ceará - Brasil \\ E-mail: vponte@fortalnet.com.br \\ Telefone: (85) 99104-9101
}

\section{Edilson Paulo}

Doutor em Contabilidade pela Universidade de São Paulo

Professor do Departamento de Finanças e Contabilidade da Universidade Federal da Paraíba

Endereço: Universidade Federal da Paraíba - Centro de Ciências Sociais Aplicadas - Programa de

Pós-Graduação em Ciências Contábeis

Endereço: Campus I - Cidade Universitária

CEP 58.051-900 - João Pessoa/PB - Brasil

E-mail: e.paulo@uol.com.br

Telefone: (83) 3216-7285

\section{Roberta Carvalho de Alencar}

Doutora em Contabilidade pela Universidade de São Paulo

Professora do Departamento de Contabilidade da Universidade Federal do Ceará

Endereço: Rua Monsenhor Bruno, 289 - Bairro Meireles

CEP: 60.115-190 - Fortaleza/Ceará - Brasil

E-mail: roberta@pradm.ufc.br

Telefone: (85) 99914-7148

Artigo recebido em 27/06/2015. Revisado por pares em 27/11/2015. Reformulado em 07/02/2017. Recomendado para publicação em 16/03/2017 por Carlos Eduardo Facin Lavarda (Editor-Chefe). Publicado em 30/04/2017. 


\section{Resumo}

O presente estudo teve como objetivo investigar a prática de gerenciamento de resultados por parte das companhias nos períodos próximos ao de realização de oferta pública de ações. A amostra do estudo compreendeu as companhias listadas na BM\&FBovespa que realizaram oferta pública de ações entre 2004 e 2013. Foram utilizados os modelos Jones Modificado (1995) e Pae (2005) e aplicou-se a técnica de dados em painel. Os resultados da pesquisa sugerem que quando as empresas gerenciam seus resultados contábeis para reduzi-los, elas buscam reduzir a variabilidade dos lucros; já quando as empresas tentam aumentar seus lucros através do gerenciamento de resultados é possível observar que essa prática é mais intensa nos trimestres ao redor da oferta pública de ações.

Palavras-chave: Gerenciamento de resultados; Oferta pública; Companhias abertas; Acumulações discricionárias; Dados em painel

\section{Abstract}

The present study aims to investigate the result management practices by companies in the periods close to share public offerings. The study sample was based on the listed companies at BM\&FBovespa that held share public offerings from 2004 to 2013. The models used were Modified Jones (1995) and Pae (2005), and it was applied the data analysis in panel. The research results suggest that when enterprises manage their accounting results to reduce them, they seek to reduce the profit variability; but when the enterprises try to increase their profits through result managements, it is possible to observe that this practice is more intense in the quarterly that is closed to the share public offerings.

Keywords: Earnings management; Public offering; Public companies; Discretionary accruals; Panel data

\section{RESUMEN}

Este estudio tuvo como objetivo investigar la práctica de la gestión de los ingresos por las empresas en periodos cercanos a la oferta pública de acciones. La muestra la formaron las compañias listadas en la BM\&FBovespa que hicieron OPI entre 2004 y 2013. Los modelos fueron utilizados Jones Modificado (1995) y Pae (2005) y se aplicó a la técnica de datos de panel. Los resultados del estudio sugieren que cuando las empresas gestionan sus resultados financieros para reducirlos, también buscan reducir la variabilidad de los beneficios, ya que cuando las empresas tratan de aumentar sus ganancias a través de la manipulación de beneficios es posible observar que esta práctica es más intensa en los trimestres en torno a la oferta pública.

Palabras clave: Gestión de los ingresos; Oferta pública; Compañias cotizadas; Acumulaciones discrecionales; Datos panel

\section{Introdução}

O atual cenário de internacionalização do mercado brasileiro tem levado as empresas do país a identificar oportunidades de expansão de suas operações ou de reestruturação de seu capital, fatores que, segundo Bonfim, Santos e Pimenta Júnior (2007), têm contribuído para aumentar o número de companhias de capital aberto.

Dentre os motivos que levam as empresas a abrir o capital, destacam-se a ampliação da base de captação de recursos, a maior flexibilidade estratégica (liquidez patrimonial), o fortalecimento da imagem institucional - devido à maior exposição no mercado -, as reestruturações societárias e a aceleração da profissionalização (BONFIM; SANTOS; PIMENTA JÚNIOR, 2007).

A oferta pública inicial de ações é o processo de abertura do capital de uma empresa em bolsa de valores, sendo bastante complexo e oneroso (como, por exemplo, despesas com coordenadores, honorários advocatícios e de auditoria, além das taxas de arquivamento na Comissão de Valores Mobiliários - CVM e na bolsa de valores), com vantagens e desvantagens, bem como obstáculos a serem transpostos e de uma série de normas e regras que devem ser observadas (VIEIRA; 
OLIVEIRA, 2007). Bonfim, Santos e Pimenta Júnior (2007) corroboram nesse sentido, alertando que os processos de abertura de capital demandam altos custos, associados ao processo e à necessidade de elevar significativamente o nível de qualidade das informações contábeis divulgadas.

Segundo Paulo (2007), a informação contábil é influenciada por critérios alternativos de mensuração e evidenciação, conhecidos por escolhas contábeis, facultando ao gestor a opção entre normas e práticas permitidas pela regulação vigente. Dessa forma, o resultado, principal produto da informação contábil, pode decorrer de ajustes contábeis de natureza discricionária, bem como não ter qualquer relação com a realidade dos fatos. Nesse momento ocorre o gerenciamento de resultados, no intuito de que estes sejam favoráveis aos executivos, independentemente dos ajustes discricionários utilizados em sua apuração.

O gerenciamento de resultados caracteriza-se como a alteração proposital dos resultados contábeis, visando alcançar e/ou atender a motivações particulares. Martinez (2001) destaca que o gerenciamento de resultados contábeis não constitui fraude contábil. Ou seja, opera-se dentro dos limites preconizados pela regulação contábil, porém nos pontos em que as normas contábeis facultam certa discricionariedade aos gerentes.

Uma oferta pública de ações é um evento crucial na vida de uma empresa, uma vez que pode ser considerada a primeira oportunidade para os fundadores perceberem ganhos de capital de suas ações (LIU; UCHIDA; GAO, 2014). Nesse contexto, as empresas procuram captar dos novos investidores o maior volume de aporte financeiro possível. No entanto, esses novos investidores procuram pagar o menor preço pela ação, no intuito de garantir o retorno esperado do seu investimento. Nessa situação, observa-se um conflito de interesses entre a administração da empresa e os novos investidores. Esse mesmo conflito pode ser visto quando acionistas detentores de uma grande proporção do capital social da empresa vendem um bloco de títulos através do mercado de capitais, pois desejam maximizar o valor das ações, obtendo bons resultados na venda para novos investidores (PAULO, 2007).

Portanto, essa situação cria a possibilidade de os administradores agirem discricionariamente, motivados a aumentar o preço das ações no momento imediatamente anterior à oferta pública de ações, levantando a possibilidade da prática de gerenciamento de resultados contábeis em períodos próximos ao de sua realização.

Nesse sentido, Bispo (2010) afirma que há sinalizações para a prática oportunista dos gestores no mercado de capitais brasileiro, já que eles se aproveitam da assimetria de informações para gerenciar resultados com o objetivo não só de obter ganhos para a empresa, mas também de valorizar e vender as ações em uma oferta pública.

Dessa forma, considerando que o atual cenário de maior flexibilidade nas normas contábeis, advinda do processo de convergência contábil e da reforma da Lei n. 6.404/1976 (BISPO, 2010), trouxe consigo instrumentos potenciais de manipulação das informações contábeis (BAPTISTA, 2009), e, ainda, que o padrão contábil brasileiro se tornou menos conservador (SANTOS, 2011; MACHADO; NAKAO, 2012), espera-se contribuir com o tema gerenciamento de resultados por companhias no contexto de oferta pública de ações, através da investigação da prática de gerenciamento de resultados nas fases próximas às de realização de ofertas públicas primárias, secundárias e mistas de ações - utilizando a metodologia de fases proposta por Gioielli (2008) - no período de 2004 a 2013, através da utilização dos modelos Jones Modificado (DECHOW; SLOAN; SWEENEY, 1995) e Pae (2005) para estimação das acumulações discricionárias.

Considerando-se a contextualização disposta anteriormente, e no intuito de ampliar o conhecimento acerca de gerenciamento de resultados contábeis, principalmente nas companhias no contexto de oferta pública de ações, procura-se, com o presente estudo, obter informações teóricoempíricas sobre o tema, na busca de respostas para o seguinte questionamento: há tendência de gerenciamento de resultados por parte das companhias nos períodos próximos ao de realização de oferta pública de ações?

Para responder à questão proposta, o presente estudo se desenvolve na expectativa de atender ao objetivo geral de investigar a prática de gerenciamento de resultados por parte das companhias nos 
períodos próximos ao de realização de oferta pública de ações.

O presente estudo busca contribuir com a discussão do tema gerenciamento de resultados e consequentemente para a discussão acerca da qualidade da informação contábil, especialmente ao redor da oferta pública de ações. Adicionalmente, pretende-se obter evidências que auxiliem na tomada de decisão dos administradores e investidores e também na fiscalização por parte dos órgãos reguladores do mercado de capitais no Brasil.

\section{Referencial Teórico}

\subsection{Gerenciamento de resultados contábeis}

Segundo Lopes e Martins (2010), a contabilidade tem como principal objetivo fornecer informações para uma ampla gama de usuários, sendo o resultado uma das mais importantes. Geralmente, é com base nesse indicador que se avalia o desempenho das empresas (MARTINEZ, 2001). Ball e Brown (1968) afirmam que o resultado contábil observado nas demonstrações contábeis é fruto de um conjunto de eventos reconhecidos por diversas práticas contábeis.

Na mesma linha, Paulo (2007) destaca que a informação contábil é influenciada por critérios alternativos de mensuração e evidenciação, conhecidos por "escolhas contábeis", facultando ao gestor a escolha entre normas e práticas permitidas pela regulação vigente.

No mesmo sentido, Becker et al. (1998) destacam que os gestores se aproveitam da assimetria de informações existente e utilizam escolhas contábeis por razões oportunistas, gerando conflitos que acabam por interferir no resultado da empresa, geralmente expropriando alguns outros stakeholders, como investidores e credores.

Healy e Wahlen (1999) afirmam que os gestores empresariais sempre irão se deparar com situações em que deverão julgar entre duas ou mais alternativas para as quais nenhum padrão contábil terá sido promulgado. Quando os gestores realizam determinadas escolhas contábeis, visando influenciar a interpretação dos stakeholders sobre o desempenho da companhia, ou atingir métricas contratuais específicas, baseadas em variáveis contábeis, caracteriza-se o gerenciamento de resultados (HEALY; WAHLEN, 1999).

Para Schipper (1989), o gerenciamento de resultados pode ser considerado uma intervenção proposital no processo de evidenciação, com a intenção de se obter algum ganho privado. Healy e Wahlen (1999) acrescentam que o gerenciamento de resultados pode ocorrer também sobre as atividades operacionais, visando iludir os investidores acerca do desempenho da companhia ou para influenciar resultados contratuais que dependem dos números contábeis informados.

No Brasil, Martinez (2001), ao apresentar o primeiro estudo sobre a temática, definiu gerenciamento de resultados como a alteração proposital dos resultados contábeis (intencional), visando alcançar, atender motivação particular. Segundo o autor, os gestores da empresa manipulariam o resultado para atender a algum objetivo particular, como a maximização da sua utilidade, em detrimento da maximização da utilidade do principal.

Ao considerar sinônimos a manipulação de resultados contábeis e o gerenciamento de resultados contábeis, Paulo (2007) define manipulação como a utilização de ações discricionárias, por parte dos administradores, para alterar a interpretação da realidade econômica e financeira da empresa.

\subsection{Estudos anteriores}

Teoh, Welch e Wong (1998) examinaram se as empresas do mercado acionário dos EUA gerenciam seus resultados de modo a obter melhores termos em sua primeira subscrição de ações. Concluíram que as firmas que vêm realizando a IPO (Initial Public Offering) possuem valor relativamente mais alto de acumulações correntes quando comparadas com outras do mesmo setor, e que as acumulações discricionárias são boas preditoras para o desempenho das ações nos três anos 
subsequentes.

Rangan (1998) estudou o efeito do gerenciamento de resultados no desempenho subsequente das ações de companhias que fizeram SEO (Seasoned Equity Offering). O autor verificou que as companhias apresentavam resultados inflados no trimestre próximo ao anúncio da SEO e no trimestre subsequente.

Com o mesmo objetivo do estudo de Teoh, Welch e Wong (1998), mas utilizando empresas do Reino Unido, Ball e Shivakumar (2008) concluíram que, em média, as empresas gerenciam seus resultados contábeis para elevar o nível de qualidade das informações contábeis antes de uma IPO, melhorando suas informações financeiras, de forma a obter ganhos na oferta pública.

Paulo (2007) investigou a oferta pública de ações e o nível de gerenciamento de resultados contábeis em companhias abertas brasileiras no período de 2000 a 2003, através da verificação de comportamentos diferentes das acumulações discricionárias ao longo do período. De acordo com os resultados obtidos, o estudo pôde confirmar a hipótese de que as empresas manipulam os números contábeis para inflacionar as ações no período da oferta pública.

Investigando também a qualidade das informações contábeis em empresas estreantes no mercado brasileiro, Gioielli (2008) analisou se a participação de gestores de private equity e venture capital (PE/VC) na governança corporativa das companhias levaria a um aumento da qualidade da informação contábil e a melhores padrões de governança corporativa. A amostra reuniu 69 empresas que realizaram IPO na BM\&FBovespa no período de janeiro de 2004 a julho de 2007. Ao se comparar companhias com investimento de $\mathrm{PE} / \mathrm{VC}$ que abriram capital com outras que não dispunham desse fundo, e que também realizaram IPO no mesmo período, constatou-se que o nível de gerenciamento de resultados contábeis (medido pelas acumulações discricionárias correntes) das companhias com investimento de $\mathrm{PE} / \mathrm{VC}$ é significativamente inferior àquele apresentado pelas empresas que não receberam esse tipo de aporte de capital. Ademais, os resultados indicaram que o período em torno da data da IPO é o momento em que as empresas gerenciam os resultados mais intensamente.

Investigando as empresas brasileiras que realizaram SEO no período de 1999 a 2008, Bispo (2010) procurou verificar se essas empresas gerenciaram seus resultados contábeis com o objetivo de aumentar o lucro ou não apresentar prejuízo. Concluiu que, de modo geral, não foi possível confirmar estatisticamente se as empresas brasileiras gerenciam seus resultados contábeis positivamente, visando valorizar suas ações em períodos próximos à SEO.

Investigando períodos anteriores à SEO, Ngo e Varela (2010) procuraram identificar se as empresas que suavizam seus resultados em tais períodos obtêm menor underprincing (efeitos positivos observados no dia de abertura e efeitos negativos observados no longo prazo). A amostra reuniu empresas dos EUA que realizaram SEO no período de 1989 a 2009. Os resultados apontaram que a suavização de resultados nos anos antes da realização de SEO está negativamente relacionada com o underprincing.

Shen, Coakley e Instefjord (2014) analisaram as relações entre o gerenciamento de resultados e o preço de oferta na IPO para uma amostra de 506 empresas chinesas que realizaram IPO no período de 1998 a 2003. Os resultados apontam que: (1) as empresas com nível superior de gerenciamento de resultados tendem a registrar melhor desempenho no primeiro dia de negociação, e, em seguida, mesmo depois de controlar o underpricing, tendem a apresentar desempenho inferior do preço das ações ao longo de um horizonte de três anos; e (2) as empresas que inicialmente apresentam pior desempenho no preço das ações tendem a obter melhor desempenho ao longo de três anos. Para os autores, os resultados apontados indicam que os investidores no mercado secundário não percebem completamente a prática de gerenciamento de resultados em períodos próximos à oferta pública.

Liu, Uchida e Gao (2014), ao investigarem gerenciamento de resultados contábeis em oferta pública de ações de empresas chinesas no período de 1999 a 2009, identificaram que: (1) os gestores que vendem suas ações no processo de IPO têm um forte incentivo para manipular os lucros para um alto preço inicial de oferta das ações; (2) os funcionários do governo têm um incentivo fazê-las manipular ganhos estatais para injeção de capital, crescimento econômico e para melhorar sua carreira; e (3) as empresas com maior alavancagem (especialmente de curto prazo) no ano pré-IPO 
gerenciam seus resultados para aumentar seus lucros.

Investigando IPO e SEO no mercado acionário brasileiro, Paulo, Cavalcante e Melo (2012) analisaram a qualidade das informações contábeis pela ótica do gerenciamento de resultados, com o intuito de verificar se há diferenças significativas nos números contábeis em companhias que realizaram oferta pública de ações e debêntures entre 2000 e 2006. Os resultados evidenciam que a oferta pública não afeta significativamente os números contábeis, sugerindo, assim, que a qualidade das informações contábeis não é influenciada pela emissão de ações e debêntures, diferentemente do encontrado em estudos com empresas dos EUA (TEOH; WELCH; WONG, 1998), britânicas (BALL; SHIVAKUMAR, 2008) e brasileiras (GIOIELLI, 2008).

Relacionando as projeções dos analistas e os resultados das IPOs brasileiras, o estudo de Santos, Pereira e Lustosa (2012) utilizou o retorno sobre o Ativo (ROA) e o retorno anormal para investigar se as companhias que realizaram IPO procuravam gerenciar seus resultados contábeis a fim de atingir as projeções dos analistas. Os resultados obtidos apresentaram indícios de gerenciamento de resultados para as firmas atingirem a projeção dos analistas de mercado relacionada ao ROA.

Ao analisar se há mais evidência de comportamento oportunista dos gestores nos períodos que antecedem as ofertas públicas de ações de companhias abertas, nas operações realizadas no Brasil no período de 2007 a 2012, Rodrigues (2013) observou a ocorrência de gerenciamento de resultados contábeis nas firmas em geral, com o objetivo de reduzir os resultados contábeis. No entanto, não foi possível afirmar com significância estatística que essa prática estivesse associada aos períodos mais próximos à realização das ofertas públicas.

Investigando gerenciamento de resultados em oferta pública de ações e o papel de gestores de capital de risco (private equity e venture capital - PE/VC), no período de janeiro de 2004 a setembro de 2010, Gioielli, Carvalho e Sampaio (2013) observaram que as IPOs de empresas com investimento de $\mathrm{PE} / \mathrm{VC}$, o gerenciamento de resultados é marginal, geralmente relacionado às características das empresas e pouco relacionado às fases da IPO. De forma diferente, para as IPOs de empresas não investidas por $\mathrm{PE} / \mathrm{VC}$ o GR é significativo, geralmente relacionado às fases da IPO e pouco relacionado às características das empresas. Finalmente, a reputação do auditor é importante apenas para as IPOs com investimento de PE/VC, sugerindo que a escolha do auditor é mais significativa para a empresa investida por $\mathrm{PE} / \mathrm{VC}$, isto é, a escolha de um auditor com boa reputação representa um compromisso de não gerenciar os resultados.

Observa-se que os estudos com as empresas brasileiras apontam em dois sentidos: a oferta pública influencia a prática de gerenciamento de resultados (PAULO, 2007; GIOIELLI, 2008; SANTOS; PEREIRA; LUSTOSA, 2012; LIU, UCHIDA; GAO, 2014), e a oferta pública não influencia a prática de gerenciamento de resultados (BISPO, 2010; PAULO; CAVALCANTE; MELO, 2012; RODRIGUES, 2013). Por outro lado, os estudos internacionais (TEOH; WELCH; WONG, 1998; RANGAN, 1998; BALL; SHIVAKUMAR, 2008) concluem que as empresas que realizam oferta pública de ações gerenciam seus resultados mais intensamente em períodos próximos à oferta e que as empresas com níveis superiores de gerenciamento de resultados apresentam menores preços das ações em períodos posteriores à IPO (SHEN; COAKLEY; INSTEFJORD, 2014). Observa-se, também, que nas empresas que suavizam os resultados contábeis nos anos anteriores à realização de SEO, a prática de alisamento está negativamente relacionada com o underprincing (NGO; VARELA, 2010).

\section{METODOLOGIA}

\subsection{Amostra e procedimento de coleta de dados}

A população do estudo reúne as companhias que realizaram oferta pública de ações entre 2004 e 2013, uma vez que, conforme Aldrighi et al. (2010), 2004 foi o ano de retomada das IPOs no Brasil. Foram excluídas da amostra as instituições financeiras e as seguradoras, por adotarem regras 
contábeis específicas, o que poderia influenciar os cálculos das variáveis dos modelos e causar algum viés à pesquisa. Também foram excluídas as empresas cujos dados não eram disponibilizados no website da BM\&FBovespa. São empresas que, em primeira análise, não estavam mais listadas na BM\&FBovespa ou que não disponibilizaram dados dos trimestres ao redor da oferta pública. A amostra do estudo é apresentada na Tabela 1.

Tabela 1 - Definição da amostra

\begin{tabular}{l|l}
\hline Especificação & Quantidade de Empresas \\
\hline População & 148 \\
\hline (-) Instituições financeiras e seguradoras & 28 \\
\hline (-) Empresas com dados indisponíveis & 29 \\
\hline Amostra & 91 \\
\hline
\end{tabular}

Fonte: Dados da pesquisa.

\subsection{Definição das hipóteses}

Para responder ao problema de pesquisa proposto no presente estudo, o gerenciamento de resultados será investigado numa perspectiva temporal, seguindo metodologia já adotada por Gioielli (2008), que investigou o gerenciamento das informações contábeis pelas empresas em processo de IPO e também em que momento ao redor desse processo essa prática é mais intensa.

Destaca-se que, diferentemente do que propunha o estudo de Gioielli (2008), que investigou as fases próximas à de realização de IPO, o presente estudo se propõe investigar a tendência de gerenciamento de resultados contábeis em períodos próximos tanto ao de realização de IPO, quanto de realização de SEO e de ofertas mistas, ou seja, nos períodos próximos ao de realização de oferta pública de ações. Gioielli (2008) define quatro fases ao redor da IPO, conforme Figura 1.

Figura 1 - Fase no estudo de gerenciamento de resultados nos trimestres anterior e posterior à IPO

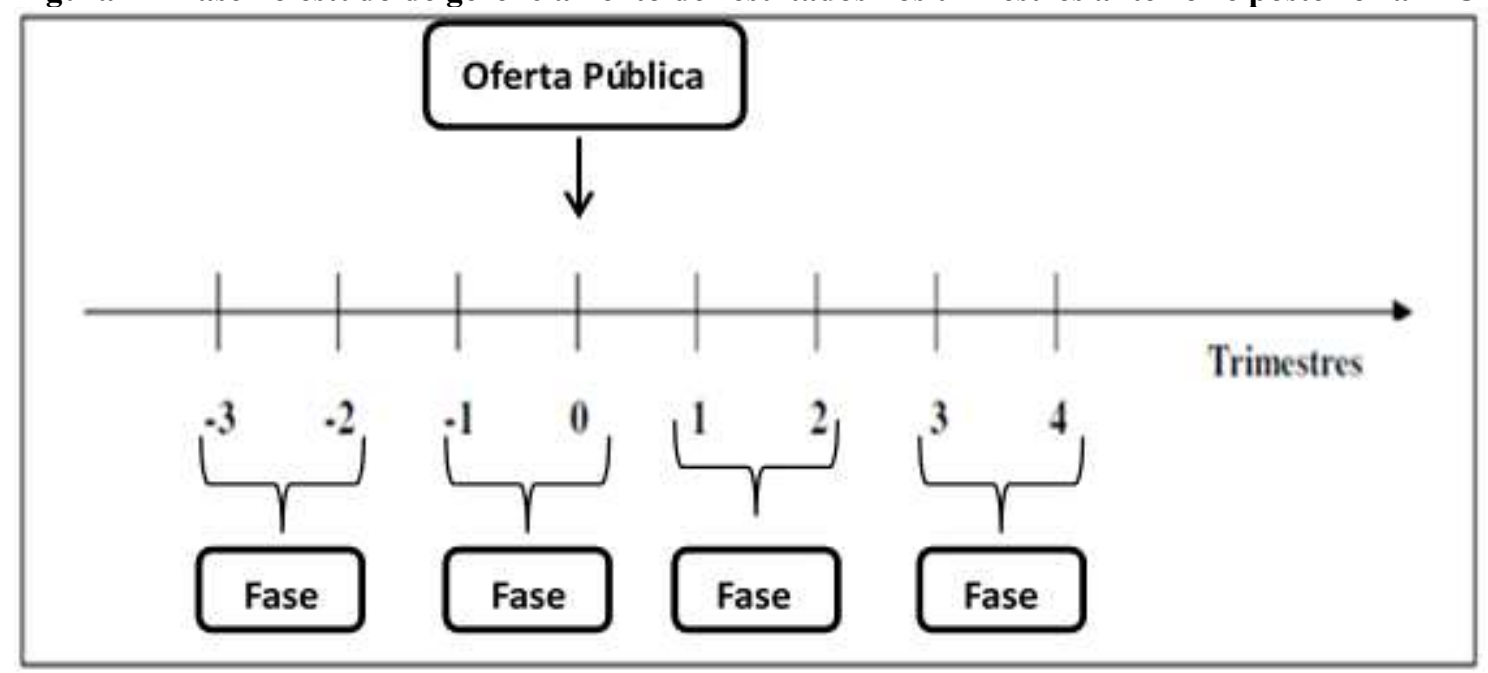

A fase 1, ou período pré-IPO, é compreendida pelos dois trimestres anteriores ao que antecede a IPO. Para Gioielli (2008), nesse período há níveis mais baixos de gerenciamento de resultados, haja vista que as empresas não se encontram no período esperado como o mais propenso à prática de gerenciamento de resultados.

A fase 2, ou período de IPO, compreende os trimestres anterior e posterior ao período de realização da IPO. Alguns estudos apontam que as empresas gerenciam seus resultados em períodos mais próximos ao da IPO (TEOH; WELCH; WONG, 1998; ROOSENBOOM; VAN DER GOOT; MERTENS, 2003; BALL; SHIVAKUMAR, 2008; LIU; UCHIDA; GAO, 2014). Para Rangan (1998), há mais motivação para o gerenciamento de resultados contábeis no trimestre imediatamente anterior ao anúncio da oferta pública, pois é nesse momento que os administradores desejam que a 
empresa seja mais bem avaliada, com o objetivo final de subir o preço inicial da ação. Também se espera que os resultados continuem a ser gerenciados no trimestre seguinte, pois uma grande variação nos resultados da empresa poderia atrair atenção "negativa" e causar prejuízos financeiros e reputacionais. Nesse mesmo sentido, Hsu e Wen (2015) apontam que os gestores tendem a gerenciar resultados contábeis durante ou após a IPO visando aumentar os preços das ações, gerando ganhos para o acionista insider e para si ao mesmo tempo. Assim, espera-se que na fase 2 as companhias que realizaram IPO gerenciem mais intensamente seus resultados do que nos trimestres imediatamente anteriores ao que antecede a IPO (fase 1).

Tem-se, então, a primeira hipótese a ser testada neste estudo, a saber:

H1: O nível de gerenciamento de resultados contábeis é, significativamente, maior nos momentos mais próximos (fase 2) à oferta pública das ações do que nos trimestres imediatamente anteriores (fase 1).

A fase 3, ou período pré-expiração da cláusula lock-up (ou vedação à negociação), diz respeito aos dois trimestres seguintes ao trimestre imediatamente posterior ao período da IPO. No Brasil, os regulamentos dos três segmentos de listagem da BM\&FBovespa estabelecem que, nos seis meses subsequentes à primeira distribuição pública de ações da companhia, o acionista controlador e os administradores não podem vender e/ou ofertar à venda quaisquer das ações e derivativos de que eram titulares imediatamente após a efetivação da distribuição (BM\&FBOVESPA, 2013).

A busca discricionária dos gestores pela redução da variabilidade dos lucros caracteriza a prática do income smoothing. Barth, Landsman e Wahlen (1995) demonstram que os preços das ações refletem um prêmio pelos riscos associados à variabilidade dos resultados e que os gestores podem reduzir os custos de capital usando seu poder discricionário na estimação de certos componentes de resultado, para reduzir a sua variabilidade. Trueman e Titman (1988) afirmam que, segundo a academia, o income smoothing é sempre benéfico para as empresas, já que reduz o custo de capital, considerando que empresas estáveis são vistas como mais confiáveis. Nesse mesmo sentido, Piqueras (2010) destaca que o income smoothing mantém os lucros próximos a lucros de períodos anteriores, reduzindo a volatilidade, a qual é utilizada para mensurar o risco em modelos financeiros. Dessa forma, espera-se que na fase 3 as empresas estreantes pratiquem o income smoothing, definindo-se a segunda hipótese do estudo, abaixo enunciada:

H2: As companhias estreantes na bolsa de valores procuram diminuir a variabilidade dos resultados contábeis nos dois períodos subsequentes (fase 3) ao da oferta pública de ações, quando comparados aos demais períodos investigados.

A fase 4, ou período pós-lock-up, compreende os dois trimestres seguintes ao trimestre imediatamente posterior ao encerramento da cláusula lock-up. Considera-se que nessa fase os administradores já não têm mais incentivos para manipular os resultados. Assim, na fase 4 , ou período pós-lock-up, acredita-se que as empresas estreantes apresentarão níveis de gerenciamento de resultados mais baixos do que na fase 2 (períodos mais próximos da IPO), haja vista que os administradores já não têm mais incentivos para manipular os resultados, porquanto a negociação de ações e de derivativos já foi realizada. Adota-se, assim, como terceira hipótese do estudo:

H3: O nível de gerenciamento de resultados antes da oferta pública de ações (fase 2) é mais alto do que no período posterior ao de vedação de negociação das ações da companhia (pós-lockup).

\subsection{Procedimentos estatísticos}

Acerca dos modelos utilizados no estudo, Paulo (2007) afirma que o Jones Modificado é um dos modelos operacionais mais utilizados nas pesquisas sobre gerenciamento de resultados (DECHOW; SLOAN; SWEENEY, 1995; CUPERTINO; MARTINEZ, 2008; PAULO; LEME, 2009). O modelo proposto por Pae (2005) tem como principal atributo aumentar o poder preditivo dos modelos Jones e Jones Modificado, por meio da inclusão de variáveis que representem o fluxo de caixa operacional e a reversão natural das acumulações anteriores (PAULO, 2007). Assim, o nível 
de gerenciamento de resultados foi estimado por meio do resíduo das regressões dos modelos Jones Modificado (DECHOW; SLOAN; SWEENEY, 1995) e Pae (2005).

Utilizou-se a análise de dados em painel para estimação dos coeficientes, e foram utilizadas as variáveis das empresas-trimestre de todo o período. Dessa forma, os coeficientes foram estimados para todo o período, e, em seguida, foi estimado o resíduo da regressão, considerando acumulações discricionárias, para cada empresa-trimestre.

As três abordagens mais comuns para análise de dados em painel são o Pooled Ordinary Least Squares - POLS (Mínimos Quadrados Ordinários Agrupados), o Fixed-Effects Model (Modelo de Efeitos Fixos) e o Random Effects (Modelo de Efeitos Aleatórios) (FÁVERO et al., 2009). A escolha do modelo mais adequado para cada análise de conta se baseou na comparação realizada pelos testes de Hausman (1978), F de Chow (1960) e LM de Breusch-Pagan (1980). O teste de Hausman (1978) define o melhor método de estimação entre efeitos fixos e efeitos aleatórios; o teste $F$ de Chow (1960) define entre efeitos fixos e POLS; e o teste $L M$ de Breusch-Pagan (1980) define entre efeitos aleatórios e POLS.

Após a definição do método mais adequado, fez-se necessária a aplicação da correção de White, com o objetivo de reduzir a heterocedasticidade dos resíduos e a sua autocorrelação serial, as quais poderão advir da heterogeneidade dos dados ou até mesmo das variáveis escolhidas.

Considerando-se que o estudo tem como objetivo geral investigar o gerenciamento de resultados nas fases ao redor da oferta pública, foi necessário obter as acumulações discricionárias por fase ao redor da oferta pública de ações, e, após observada a normalidade dos dados, foi realizado o teste não-paramétrico de Kruskal-Wallis para avaliação das hipóteses do estudo. Destaca-se ainda que para a verificação das hipóteses do estudo, optou-se por analisar o nível de gerenciamento de resultados contábeis separando os accruals positivos dos negativos. O objetivo dessa medida foi evitar a distorção dos resultados.

Para verificação da hipótese 1 , de que o nível de gerenciamento de resultados contábeis é, significativamente, mais elevado nos momentos mais próximos à oferta pública das ações do que nos trimestres imediatamente anteriores ao que antecede a oferta, foram comparadas as acumulações discricionárias nas fases 1 e 2.

Para verificação da hipótese 2, de que as companhias estreantes na bolsa de valores procuram diminuir a variabilidade dos resultados contábeis nos dois períodos subsequentes à oferta pública de ações, quando comparados aos demais períodos investigados, foi comparada a fase 3 com as fases 1 , 2 e 4.

Para verificação da hipótese 3, de que o nível de gerenciamento de resultados antes da oferta pública de ações é mais elevado do que no período posterior ao de vedação de negociação das ações da companhia (pós-lock-up), foram comparadas as acumulações discricionárias nas fases 2 e 4.

Os testes estatísticos foram realizados com auxílio do programa Stata ${ }^{\circledR}$, versão 12, de análise estatística para uso em pesquisas; para organização das tabelas e amostras, utilizou-se a planilha eletrônica Excel.

\section{Resultados}

Para facilitar o entendimento, esta seção é dividida em quatro subseções. Na primeira são apresentados os resultados das regressões para os modelos Jones Modificado (DECHOW; SLOAN; SWEENEY, 1995) e Pae (2005); na segunda é apresentado o nível de gerenciamento de resultados ao redor da oferta pública de ações; na terceira subseção são apresentados os resultados do teste não paramétrico de Kruskal-Wallis e, por fim, uma síntese dos resultados.

\subsection{Análise da escolha dos modelos de regressão}

Conforme apontado na metodologia, foram selecionados os modelos Jones Modificado (DECHOW; SLOAN; SWEENEY, 1995) e Pae (2005) para estimação do nível de gerenciamento de 
resultados contábeis. Após o cálculo das acumulações totais - conforme apontado na seção 3.4.1 - e coleta das variáveis explicativas, os modelos foram testados adotando-se a análise de dados em painel por três métodos - efeitos fixos, efeitos aleatórios e POLS. Foram utilizados os testes $F$ de Chow (1960), de Hausman (1978) e LM de Breusch Pagan (1980) para a escolha do método mais adequado para o conjunto de dados.

Após a determinação do método mais adequado, foi aplicado o método de correção de White (1980) à heterocedasticidade para o método POLS no modelo Jones Modificado (DECHOW; SLOAN; SWEENEY, 1995) e para o método de efeitos fixos para o modelo Pae (2005). Os resultados das regressões são destacados na Tabela 2.

Tabela 2 - Resultados das regressões após a correção de White

\begin{tabular}{|c|c|c|c|c|}
\hline \multicolumn{5}{|c|}{\begin{tabular}{|l} 
Modelo Jones Modificado (1995) \\
\end{tabular}} \\
\hline \multicolumn{5}{|c|}{ TAit $=\alpha i+\beta 1 i(\Delta R E V i t-\Delta R E C i t)+\beta 2 i($ PPEit $)+\varepsilon i t$} \\
\hline \multicolumn{5}{|c|}{ POLS } \\
\hline & Coeficiente & Erro Padrão & $\mathbf{T}$ & P-Valor \\
\hline Constante & $-0,0298473$ & 0,0201101 & $-1,48$ & 0,138 \\
\hline$\triangle R E V i t-\triangle R E C i t$ & $-0,1031474$ & 0,0773488 & $-1,33$ & 0,183 \\
\hline PPEit & $-0,0219064$ & 0,004068 & $-5,39$ & $0,000 * * *$ \\
\hline \multicolumn{3}{|c|}{$\mathbf{R}^{2}$} & \multicolumn{2}{|c|}{0,0632} \\
\hline \multicolumn{3}{|c|}{ Prob. $>$ F } & \multicolumn{2}{|c|}{$\mathbf{0 , 0 0 0}$} \\
\hline \multicolumn{5}{|c|}{ Modelo Pae (2005) } \\
\hline \multicolumn{5}{|c|}{ TAit $=\alpha(1 /$ At-1) $+\beta 1(\Delta$ Rit $)+\beta 2($ PPEit $)+\beta 3($ FCOit $)+\beta 4($ FCOit-1 $)+\beta 5($ TAit -1$)+\varepsilon i t$} \\
\hline \multicolumn{5}{|c|}{ Método de Efeitos Fixos } \\
\hline & Coeficiente & Erro Padrão & $\mathbf{T}$ & P-Valor \\
\hline Constante & 0,0152389 & 0,0063418 & 2,40 & $0,018 * *$ \\
\hline$\Delta$ Rit & 0,0086938 & 0,0107965 & 0,81 & 0,423 \\
\hline PPEit & $-0,0060558$ & 0,0238239 & $-0,25$ & 0,800 \\
\hline FCOit & $-0,9508235$ & 0,0233472 & $-40,73$ & $0,000 * * *$ \\
\hline FCOit-1 & 0,0138242 & 0,0082354 & 1,68 & $0,097 *$ \\
\hline TAit-1 & $-0,0247394$ & 0,0322926 & $-0,77$ & 0,446 \\
\hline \multicolumn{3}{|c|}{$\mathbf{R}^{\mathbf{2}}$} & \multicolumn{2}{|c|}{0,9214} \\
\hline \multicolumn{3}{|c|}{ Prob. $>$ F } & \multicolumn{2}{|c|}{0,000} \\
\hline
\end{tabular}

*** Significante a $1 \%$

** Significante a $5 \%$

* Significante a $10 \%$

Fonte: Dados da pesquisa.

Observa-se o baixo poder explicativo do modelo Jones Modificado (DECHOW; SLOAN; SWEENEY, 1995), com $\mathrm{R}^{2}$ de 0,0632. Destaca-se que das duas variáveis utilizadas no modelo, apenas "imobilizado" foi significante ao nível de 1\%. No entanto, mesmo o coeficiente não apresentando significância estatística, optou-se por manter a variável "variação das receitas menos os recebíveis" no modelo, seguindo procedimentos adotados por Lopes e Tukamoto (2007) e Bispo (2010), dada a significância da estatística $-F$ de $1 \%$. Os coeficientes das variáveis apresentaram o sinal esperado.

O modelo Pae (2005) apresenta poder explicativo melhor que o do modelo Jones Modificado (DECHOW; SLOAN; SWEENEY, 1995), com R² de 0,9214. Destaca-se que as variáveis "fluxo de caixa do período" e "fluxo de caixa do período anterior" são estatisticamente diferentes de zero. Também para esse modelo, verifica-se que os coeficientes das variáveis explicativas apresentaram o comportamento esperado.

Apesar de reconhecer que o modelo Jones Modificado (DECHOW; SLOAN; SWEENEY, 1995) apresenta baixo poder explicativo, inclusive com coeficientes não significantes, e que o modelo Pae (2005), apesar de apresentar um alto poder explicativo também apresenta coeficientes não significantes, decidiu-se mantê-los para estimação do nível de gerenciamento de resultados a partir das acumulações discricionárias. Destaca-se que esses achados corroboram aquele apontado por 
Paulo (2007) ao investigar o poder explicativo dos modelos de estimação do nível de gerenciamento de resultados.

\subsection{Análise descritiva do nível de gerenciamento de resultados contábeis}

Buscando-se atingir o objetivo geral do estudo, foram estimadas as acumulações discricionárias para cada empresa-trimestre. Importa destacar que as fases ao redor da oferta pública de ações apresentam quantidades distintas de observações, pois, conforme apontado na metodologia, algumas empresas não disponibilizavam os dados das variáveis explicativas dos modelos utilizados.

A Tabela 3 apresenta os dados descritivos do nível de gerenciamento de resultados contábeis na fase compreendida pelos dois trimestres anteriores ao trimestre que antecede a oferta pública de ações (fase 1), na fase compreendida pelos trimestres anterior e posterior à oferta pública de ações (fase 2), na fase de vedação à negociação das ações das companhias ou compreendida pelos dois trimestres logo após o trimestre imediatamente posterior à oferta pública de ações (fase 3), e na fase pós-vedação à negociação das ações das companhias compreendida pelos dois trimestres logo após o trimestre imediatamente posterior ao encerramento da vedação à negociação (fase 4), segregando os accruals negativos dos positivos conforme apontado na Metodologia.

Tabela 3 - Estatística descritiva dos níveis de gerenciamento de resultados

\begin{tabular}{l|l|l|l|l|l|l|l|l|l|l|l|l}
\hline \multirow{2}{*}{ Modelo } & \multicolumn{3}{|c|}{ Fase 1 } & \multicolumn{3}{c|}{ Fase 2 } & \multicolumn{3}{c|}{ Fase 3 } & \multicolumn{3}{c}{ Fase 4 } \\
\cline { 2 - 12 } & $\mathbf{N}$ & Média & $\begin{array}{l}\text { Desvio- } \\
\text { padrão }\end{array}$ & $\mathbf{N}$ & Média & $\begin{array}{l}\text { Desvio- } \\
\text { padrão }\end{array}$ & $\mathbf{N}$ & Média & $\begin{array}{l}\text { Desvio- } \\
\text { padrão }\end{array}$ & N & Média & $\begin{array}{l}\text { Desvio- } \\
\text { padrão }\end{array}$ \\
\hline $\begin{array}{l}\text { Jones } \\
\begin{array}{l}\text { Modificado } \\
\text { Negativos }\end{array}\end{array}$ & 103 & $-0,05$ & 0,03 & 106 & $-0,05$ & 0,02 & 111 & $-0,05$ & 0,2 & 120 & $-0,05$ & 0,02 \\
\hline $\begin{array}{l}\text { Jones } \\
\text { Modificado } \\
\text { Positivos }\end{array}$ & 21 & 0,04 & 0,07 & 22 & 0,03 & 0,25 & 19 & 0,04 & 0,07 & 21 & 0,04 & 0,05 \\
\hline $\begin{array}{l}\text { Pae } \\
\text { Negativos }\end{array}$ & 24 & $-0,16$ & 0,25 & 63 & $-0,13$ & 0,19 & 61 & $-0,06$ & 0,26 & 105 & $-0,26$ & 0,39 \\
\hline $\begin{array}{l}\text { Pae } \\
\text { Positivos }\end{array}$ & 14 & 0,02 & 0,14 & 50 & 0,11 & 0,20 & 86 & 0,10 & 0,14 & 40 & 0,08 & 0,14 \\
\hline
\end{tabular}

Fonte: Dados da pesquisa.

As acumulações discricionárias estimadas pelo modelo Jones Modificado (DECHOW; SLOAN; SWEENEY, 1995) apresentam-se em valores absolutos com médias iguais para os valores negativos. As acumulações discricionárias positivas apresentam médias iguais na fase compreendida pelos trimestres anteriores aos trimestres anterior e posterior ao período da oferta pública (fase 1), na fase de vedação à negociação (fase 3 ) e na fase de pós-vedação à negociação (fase 4) e valor absoluto menor quando comparada com as demais na fase compreendida pelos trimestres imediatamente ao redor da oferta pública (fase 2). Esses resultados permitem inferir que quando as empresas gerenciam seus resultados para diminuí-lo, o nível de gerenciamento é o mesmo nas quatro fases. Já quando as empresas gerenciam seus resultados para aumentá-lo, o nível é o mesmo nas fases 1 , 3, e 4 e as companhias gerenciam com menor intensidade nos trimestres ao redor da oferta pública de ações (fase 2).

Os resultados do modelo Pae (2005), diferentemente do apresentado pelo modelo Jones Modificado (DECHOW; SLOAN; SWEENEY, 1995), mostram que em valores absolutos as médias das acumulações discricionárias são consideravelmente divergentes, tanto para os valores absolutos positivos quanto para os negativos. As acumulações discricionárias negativas apresentaram média mais elevada na fase posterior ao período seguinte ao de vedação de negociação das ações das companhias (fase 4) e mais baixa na fase de vedação à negociação (fase 3). Esses resultados permitem apontar que quando as empresas gerenciam seus resultados para reduzi-los, elas gerenciam intensamente nos trimestres anteriores a IPO, durante a IPO e após a vedação de negociação das ações 
da companhia.

Ainda sobre os resultados do modelo Pae (2005), acerca das acumulações discricionárias positivas nas fases ao redor da oferta pública de ações, a média mais elevada apresenta-se na fase compreendida pelos trimestres imediatamente ao redor da oferta pública (fase 2) e mais baixa na fase compreendida pelos trimestres anteriores aos trimestres anterior e posterior ao da oferta pública (fase 1). As médias das fases posterior ao período seguinte ao de vedação de negociação das ações das companhias (fase 4) e de vedação à negociação (fase 3) apresentam médias semelhantes, sugerindo o mesmo nível de gerenciamento de resultados. A partir desses resultados é possível inferir que quando as empresas gerenciam seus resultados para aumentá-lo, há maior intensidade dessa prática na fase compreendida pelos trimestres imediatamente ao redor da oferta pública (fase 2).

\subsection{Análise dos testes para comparação das fases}

Com o objetivo de testar as hipóteses levantadas no estudo, investigou-se se há diferença significativa nos níveis de gerenciamento de resultados das diversas fases ao redor da oferta pública de ações.

Inicialmente, aplicou-se o teste de normalidade dos dados de Kolmogorov-Smirnov, obtendose evidências para se rejeitar a hipótese da normalidade do nível de gerenciamento por fase anterior ou posterior ao período da oferta pública de ações. Assim, optou-se por aplicar o teste nãoparamétrico de Kruskal-Wallis para investigar se o nível de gerenciamento de resultados é significativamente diferente entre as fases anterior e posterior ao período da oferta pública de ações.

A Tabela 4 apresenta os resultados do teste não-paramétrico de Kruskal-Wallis para cada modelo utilizado para estimação das acumulações discricionárias.

Tabela 4 - Resultados do teste de Kruskal-Wallis para comparação do nível de gerenciamento de resultados das fases ao redor da oferta pública de ações

\begin{tabular}{|c|c|c|c|c|c|c|c|c|}
\hline \multirow{2}{*}{ Fases } & \multicolumn{2}{|c|}{ JM Negativos } & \multicolumn{2}{|c|}{ JM Positivos } & \multicolumn{2}{|c|}{ Pae Negativos } & \multicolumn{2}{|c|}{ Pae Positivos } \\
\hline & $\mathbf{Z}$ & Sig. & $\mathbf{Z}$ & Sig. & $\mathbf{Z}$ & Sig. & $\mathbf{Z}$ & Sig. \\
\hline 1 e 2 & $-0,47$ & 0,64 & $-0,58$ & 0,56 & $-1,25$ & 0,210 & $-3,20$ & $0,001 * * *$ \\
\hline $1 \mathrm{e} 3$ & $-0,24$ & 0,81 & $-0,28$ & 0,78 & $-3,32$ & $0,001 * * *$ & $-2,49$ & $0,013 * * *$ \\
\hline $1 \mathrm{e} 4$ & $-0,60$ & 0,55 & $-0,24$ & 0,81 & $-1,48$ & 0,140 & $-1,52$ & 0,129 \\
\hline 2 e 3 & $-0,93$ & 0,35 & $-0,89$ & 0,37 & $-2,47$ & $0,013 * *$ & $-1,32$ & 0,188 \\
\hline $2 \mathrm{e} 4$ & $-0,42$ & 0,67 & $-0,27$ & 0,79 & $-3,72$ & $0,00 * * *$ & $-2,17$ & $0,03 * *$ \\
\hline 3 e 4 & $-1,06$ & 0,29 & $-0,61$ & 0,54 & $-5,97$ & $0,000 * * *$ & $-1,22$ & 0,224 \\
\hline
\end{tabular}

*** Significante a $1 \%$

** Significante a $5 \%$

Fonte: Dados da pesquisa.

Para o modelo Jones Modificado (DECHOW; SLOAN; SWEENEY, 1995), observa-se que não há diferença significativa no nível de gerenciamento de resultados das empresas nas diversas fases anteriores e posteriores ao período da oferta pública de ações. Contudo, deve-se destacar o baixo poder explicativo do modelo e que, das duas variáveis independentes do modelo, apenas uma se mostrou significante.

Destaca-se que, para o modelo Pae (2005) para as acumulações discricionárias positivas, os resultados dos testes de diferenças do nível de gerenciamento de resultados das fases ao redor da oferta pública de ações apontam que a fase compreendida pelos trimestres imediatamente anteriores àquele que antecede a oferta pública de ações (fase 1) e a fase compreendida pelos trimestres mais próximos à oferta pública de ações (fase 2) apresentaram níveis estatisticamente diferentes.

Ao nível de significância de 5\% é possível afirmar que a fase compreendida pelos trimestres mais próximos à oferta pública de ações (fase 2) e a fase posterior ao período de vedação à negociação das ações das companhias (fase 4) apresentaram níveis de gerenciamento de resultados estatisticamente diferentes. Destaca-se que esses achados são válidos tanto para as empresas que 
gerenciam seus resultados para reduzir quanto para aumentar seus lucros.

Para as acumulações discricionárias negativas, observa-se que a fase compreendida pelos dois trimestres subsequentes à oferta pública de ações (fase 3) apresentou níveis de gerenciamento de resultados estatisticamente diferentes daqueles apresentados na fase compreendida pelos trimestres imediatamente anteriores ao que antecede a oferta pública de ações (fase 1), na fase compreendida pelos trimestres mais próximos à oferta pública de ações (fase 2) e na fase posterior ao período de vedação à negociação das ações das companhias (fase 4).

Para complementação da análise dos resultados, optou-se por investigar o comportamento do lucro líquido das empresas nas fases ao redor da oferta pública de ações. A Tabela 5 apresenta os dados descritivos do lucro líquido.

Tabela 5 - Estatística descritiva do lucro líquido

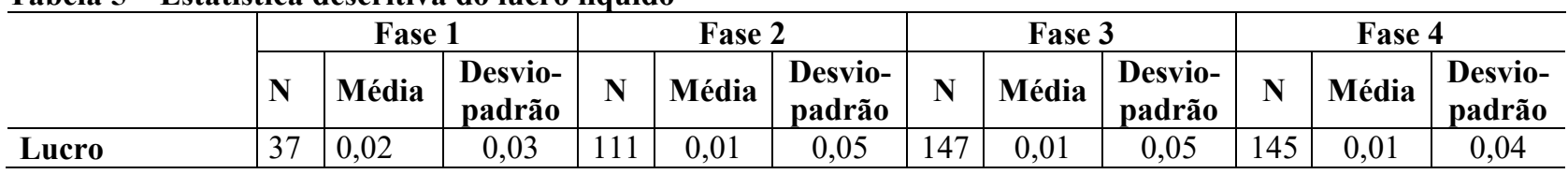

Fonte: Dados da pesquisa.

A partir da Tabela 5 é possível afirmar que em valores absolutos as médias dos lucros são semelhantes, apresentando valor mais elevado na fase compreendida pelos trimestres anteriores aos trimestres anterior e posterior ao período da oferta pública (fase 1) e valores iguais nas fases compreendidas pelos trimestres imediatamente ao redor da oferta pública (fase 2), de vedação à negociação (fase 3) e de pós-vedação à negociação (fase 4). Para todas as fases, observou-se sinal positivo do lucro líquido, podendo-se inferir que as empresas buscam apresentar resultados positivos.

A Tabela 6 apresenta os resultados do teste não-paramétrico de Kruskal-Wallis para o lucro líquido das companhias.

Tabela 6 - Resultados do teste de Kruskal-Wallis para comparação do lucro líquido nas fases ao redor da oferta pública de ações

\begin{tabular}{c|c|c}
\hline \multirow{2}{*}{ Fases } & \multicolumn{2}{|c}{ Lucro Líquido } \\
\cline { 2 - 3 } & Qui-quadrado & $0,068^{*}$ \\
\hline 1 e 2 & 3,337 & 0,708 \\
\hline 1 e 3 & 0,140 & 0,631 \\
\hline 1 e 4 & 0,231 & $0,003^{* * *}$ \\
\hline 2 e 3 & 8,891 & $0,048^{* *}$ \\
\hline 2 e 4 & 3,921 & 0,165 \\
\hline
\end{tabular}

*** Significante a $1 \%$

** Significante a $5 \%$

*Significante a $10 \%$

Fonte: Dados da pesquisa.

Destaca-se que, para o lucro líquido, os resultados dos testes apontaram que a fase compreendida pelos trimestres mais próximos à oferta pública de ações (fase 2) e a fase posterior ao período de vedação à negociação das ações das companhias (fase 4) apresentaram lucros estatisticamente diferentes ao nível de significância de $1 \%$.

Ainda sobre o lucro líquido, pode-se afirmar ao nível de significância de $10 \%$ que a fase compreendida pelos trimestres imediatamente anteriores ao que antecede a oferta pública de ações (fase 1) e a fase compreendida pelos trimestres mais próximos à oferta pública de ações (fase 2) apresentaram lucros estatisticamente diferentes.

A partir dos resultados apontados na Tabela 6 é possível afirmar que as empresas apresentam lucros estatisticamente iguais nas fases 1,3 e 4 e que a fase 2 apresenta lucro distinto das demais fases. 


\subsection{Síntese dos resultados}

Pode-se destacar que os modelos Jones Modificado (1995) e Pae (2005) apresentam problemas de estimação ao apresentarem parâmetros com baixa significância estatística. $\mathrm{O}$ modelo Jones Modificado apresentou baixo poder explicativo, já que das suas duas variáveis independentes apenas uma se mostrou significante, o que pode ser considerado uma limitação do presente estudo.

Assim, ao analisar os níveis de gerenciamento de resultados pelo modelo Jones Modificado (DECHOW; SLOAN; SWEENEY, 1995), observou-se que não há diferença significativa nas fases anteriores e posteriores ao período da oferta pública de ações.

Os resultados do modelo Pae (2005) para as acumulações discricionárias negativas apresentaram média mais elevada na fase posterior ao período seguinte ao de vedação de negociação das ações das companhias (fase 4) e mais baixa na fase de vedação à negociação (fase 3). Acerca das acumulações discricionárias positivas nas fases ao redor da oferta pública de ações, a média mais elevada apresenta-se na fase compreendida pelos trimestres imediatamente ao redor da oferta pública (fase 2) e mais baixa na fase compreendida pelos trimestres anteriores aos trimestres anterior e posterior ao da oferta pública (fase 1).

Ao se verificar que o nível de gerenciamento de resultados contábeis para as acumulações discricionárias negativas é mais elevado na fase 4, os resultados refutam os achados de Gioelli (2008), segundo o qual o nível de gerenciamento de resultados na fase 2 apresentados pelas empresas da amostra é mais elevado do que nas fases 1 e 4 . No mesmo sentido, ao apresentar maiores médias absolutas dos níveis de gerenciamento de resultados nas fases 1 e 4, os achados refutam o apontado por Rangan (1998), o qual afirma que as fases 1 e 4 são as fases "sem incentivo", em que as empresas devem apresentar os mais baixos níveis de gerenciamento de resultados.

Ainda sobre as acumulações discricionárias negativas estimadas pelo modelo Pae (2005), rejeita-se a hipótese 1, de que o nível de gerenciamento de resultados contábeis é, significativamente, mais elevado nos momentos mais próximos (fase 2) à oferta pública das ações do que nos trimestres imediatamente anteriores (fase 1) àquele que antecede a oferta pública de ações, pelo fato de a média absoluta da fase 1 ser maior que a da fase 2 e não serem estatisticamente significantes. Esses resultados refutam os achados de Teoh, Welch e Wong (1998), Ball e Shivakumar (2008) e Gioelli (2008), os quais apontaram que na fase 2 as empresas gerenciam seus resultados com mais intensidade.

Já a hipótese 2, de que as companhias estreantes na bolsa de valores procuram diminuir a variabilidade dos resultados contábeis nos dois períodos subsequentes (fase 3) à oferta pública de ações, quando comparados aos demais períodos investigados, não pode ser rejeitada, pois a fase 3 é estatisticamente diferente das fases 1,2 e 4 .

Apesar da apresentação de níveis de gerenciamento de resultados estatisticamente diferentes nas fases 2 e 4, rejeita-se a hipótese 3, de que o nível de gerenciamento de resultados nos trimestres anterior e posterior ao período da oferta pública de ações (fase 2) é mais elevado do que no período posterior ao intervalo de vedação de negociação das ações da companhia (pós-lock-up), pois a média absoluta da fase 4 é maior que a da fase 2 .

Ao se verificar que o nível de gerenciamento de resultados contábeis para as acumulações discricionárias positivas é mais elevado na fase 2, os resultados corroboram os achados de Gioelli (2008), segundo o qual o nível de gerenciamento de resultados na fase 2 apresentados pelas empresas da amostra é mais elevado do que nas fases 1 e 4.

Observa-se que os níveis de gerenciamento de resultados contábeis são estatisticamente diferentes nas fases 1 e 2 e ainda que a média absoluta da fase 2 é maior que a da fase 1 , portanto, não se rejeita a hipótese 1 , de que o nível de gerenciamento de resultados contábeis é, significativamente, mais elevado nos momentos mais próximos (fase 2) à oferta pública das ações do que nos trimestres imediatamente anteriores (fase 1) àquele que antecede a oferta pública de ações. 
Esses resultados corroboram os achados de Teoh, Welch e Wong (1998), Ball e Shivakumar (2008) e Gioelli (2008), os quais apontaram que na fase 2 as empresas gerenciam seus resultados com mais intensidade.

Já a hipótese 2, de que as companhias estreantes na bolsa de valores procuram diminuir a variabilidade dos resultados contábeis nos dois períodos subsequentes (fase 3) à oferta pública de ações, quando comparados aos demais períodos investigados, deve ser rejeitada, pois a fase 3 não é estatisticamente diferente das fases 2 e 4.

Com relação à hipótese 3 do estudo, observa-se que os níveis de gerenciamento de resultados estatisticamente diferentes nas fases 2 e 4 e que a média absoluta da fase 2 é maior que a da fase 4 , portanto, não se rejeita a hipótese 3 , de que o nível de gerenciamento de resultados nos trimestres anterior e posterior ao período da oferta pública de ações (fase 2) é mais elevado do que no período posterior ao intervalo de vedação de negociação das ações da companhia (pós-lock-up).

A partir do comportamento do lucro líquido evidenciado nas Tabelas 5 e 6 , sugere-se que as empresas gerenciem seus resultados contábeis para diminuir a variabilidade do lucro líquido nas fases 1,2 e 4, gerenciando negativamente e na mesma intensidade nas fases 1 e 4 e gerenciando positivamente na fase 3 . Também, se destaca que, buscando apresentar lucros melhores na fase 2 , as empresas gerenciam negativamente com menos intensidade, apresentando lucros distintos e melhores quando comparados com outras fases.

\section{Considerações Finais}

Esta pesquisa teve como objetivo geral investigar a prática de gerenciamento de resultados por parte das companhias nos períodos próximos ao de realização de oferta pública de ações, já que a partir das "escolhas contábeis" os administradores podem agir discricionariamente, motivados a aumentar o preço das ações no momento imediatamente anterior à oferta pública de ações, levantando a possibilidade da prática de gerenciamento de resultados contábeis em períodos próximos ao de sua realização.

Ao se verificar o nível de gerenciamento de resultados contábeis para as acumulações discricionárias negativas, é possível afirmar que quando as empresas gerenciam seus resultados para reduzi-los, elas buscam utilizar essa prática para reduzir a variabilidade dos lucros, caracterizando a prática do income smoothing, objetivando manter os lucros em determinado patamar, evitando flutuações excessivas que poderiam aumentar a percepção de risco (KANAGARETNAM; LOBO; YANG, 2004) e os custos de capital (BARTH; LANDSMAN; WAHLEN, 1995; TRUEMAN; TITMAN,1988).

Analisando o nível de gerenciamento de resultados contábeis para as acumulações discricionárias positivas, pode-se afirmar que quando as empresas gerenciam seus resultados para aumentá-lo, elas estão utilizando dessa prática mais intensamente no período imediatamente ao redor da oferta pública de ações, uma vez que buscam que a empresa seja mais bem avaliada, com objetivo de subir o preço inicial da ação. Esses resultados corroboram com Rangan (1998). Assim, devido ao alto grau de assimetria informacional no momento do IPO, os investidores são obrigados a confiar nas informações divulgadas nos prospectos institucionais de distribuição pública, fazendo com que os gestores manipulem resultados contábeis durante ou após a IPO visando aumentar os preços das ações, gerando ganhos para o acionista insider e para si ao mesmo tempo (HSU; WEN, 2015).

O presente estudo contribuiu com a discussão do tema gerenciamento de resultados e obteve evidências de que os investidores e os órgãos de fiscalização e regulação do mercado de capitais no Brasil devem buscar alternativas para detectar e/ou inibir práticas oportunistas da administração das companhias durante a oferta pública de ações.

Por fim, sugere-se, para pesquisas futuras, o acréscimo de outros modelos de estimação das acumulações discricionárias, devido ao baixo poder explicativo do modelo Jones Modificado (DECHOW; SLOAN; SWEENEY, 1995); a comparação do contexto brasileiro com outros países emergentes, bem como a inclusão das ofertas de debêntures. 


\section{Referências}

ALDRIGHI, D. M. et al. As ofertas públicas iniciais na Bovespa no período recente: características das empresas, estrutura de propriedade e de controle, e desempenho. In: Encontro Nacional de Economia da Associação Nacional dos Centros de Pós-Graduação em Economia, 38., 2010, Salvador. Anais... Salvador: Anpec, 2010.

BALL, R.; BROWN, P. An empirical evaluation of accounting income numbers. Journal of Accounting Research, v.6, n. 3, p. 159-178, 1968.

; SHIVAKUMAR, L. The role of accruals in asymmetrically timely gain and loss recognition. Journal of Accounting Research, Chicago, v. 44, n. 2, p. 207-242, May, 2006. $<$ http://dx.doi.org/10.1111/j.1475-679X.2006.00198.x>

; SHIVAKUMAR, L. Earnings quality at initial public offerings. Journal of Accounting and Economics, Amsterdam, v. 45, n. 2, p.324-349, Aug. 2008. $<\mathrm{http}: / /$ dx.doi.org/10.1016/j.jacceco.2007.12.001>

BAPTISTA, E. M. B. Ganhos em transparência versus novos instrumentos de manipulação: o paradoxo das modificações trazidas pela lei $n^{\circ}$ 11.638. Revista de Administração de Empresas, v. 49, n. 2, p. 234-239, 2009.

BARTH, M. E.; LANDSMAN W. R.; WAHLEN, J. M. Fair value accounting: effects on banks' earnings volatility, regulatory capital and value of contractual cash flows. Journal of Banking and Finance, v. 19, n. 2, p. 577-605, 1995. http://dx.doi.org/10.1016/0378-4266(94)00141-O

BECKER, C. L.; DEFOND, M.L.; JIAMBALVO, J.; SUBRAMANYAM, K.R. The effect of audit quality on earnings management. Contemporary Accounting Research, v. 15, n. 1, P.1-24, 1998.

BISPO, O. N. de A. Gerenciamento de resultados contábeis e o desempenho das ofertas públicas subsequentes de ações de empresas brasileiras. 2010. 145 f. Dissertação (Mestrado) Faculdade de Ciências Econômicas, Departamento de Ciências Contábeis, Universidade Federal de Minas Gerais, Belo Horizonte.

; LAMOUNIER, W. M. Gerenciamento de resultados contábeis e o desempenho das ofertas públicas subsequentes de ações de empresas brasileiras. In: Congresso USP de Controladoria e Contabilidade, 11, 2011, São Paulo. Anais... São Paulo.

BM\&FBOVESPA - BOLSA DE VALORES, MERCADORIAS E FUTUROS. Empresas listadas. 2013. Disponível em: $<$ http://www.bmfbovespa.com.br/Cias-Listadas/EmpresasListadas/BuscaEmpresaListada.aspx?idioma=pt-br>. Acesso em: 27 out. 2013.

BONFIM, L. P. M.; SANTOS, C.M.; PIMENTA JÚNIOR, T. Processos de abertura de capital de empresas brasileiras em 2004 e 2005: razões e percepções. RAUSP - Revista de Administração, v. 42 , n.4 p. 524-534, 2007.

BREUSCH, T.S.; PAGAN, A.R. The lagrange multiplier test and its applications to model specification in econometrics. Review of Economic Studies, v. 47, n. 1, p. 239-253, 1980. http://dx.doi.org/10.2307/2297111 
CHOW, G. C. Tests of equality between sets of coefficients in two linear regressions.

Econometrica, v. 28, n. 3, p. 591-605, 1960. http://dx.doi.org/10.2307/1910133

CUPERTINO, C. M.; MARTINEZ, A. L. Qualidade da auditoria e earnings management: risk assessment através do nível de accruals discricionários. Revista Contabilidade Vista e Revista, v. 19, n. 3, p. 69-93, 2008.

DECHOW, P. M.; SLOAN, R.G.; SWEENEY, A. P. Detecting earnings management. The Accounting Review, v. 70, n. 2, p. 193-225, 1995.

FÁVERO, L. P. et al. Análise de Dados: Modelagem Multivariada para Tomada de Decisões. Rio de Janeiro: Elsevier, 2009.

GIOIELLI, S. P. O. Os gestores de 'private equity' e 'venture capital' influenciam a governança corporativa das investidas? Evidências das empresas estreantes na Bovespa. 2008. 107 f. Dissertação (Mestrado em Administração de Empresas) - Escola de Administração de Empresas de São Paulo, Fundação Getúlio Vargas, São Paulo.

GIOIELLI, S. O.; CARVALHO, A. G.; SAMPAIO, J. O. Capital de risco e gerenciamento de resultados em IPOs. Brazilian Business Review, v. 10, n. 4, p. 32-68, 2013.

HAUSMAN, J.A. Specification tests in econometrics. Econometrica, v. 46, n. 6, p. 1251-1271, 1978. http://dx.doi.org/10.2307/1913827

HEALY P. M.; WAHLEN, J. M. A review of the earnings management literature and its implications for standard setting. Accounting Horizons, v. 13, n. 4, p.363-383, 1999. http://dx.doi.org/10.2308/acch.1999.13.4.365

HSU, M.F.; WEN, S.Y. The roles of institutional investors and insiders in earnings management around initial public offering firms in Taiwan. International Journal of Economics and Financial Issues, v.5, n.2, p. 340-353, 2015.

JONES, J. J. Earnings management during import relief investigations. Journal of Accounting Research, v. 29, n. 1, p. 193-228, 1991. http://dx.doi.org/10.2307/2491047

KANAGARETNAM; K.; LOBO; G.J.; YANG, D.H. Joint tests of signaling and income smoothing through bank loan loss provisions. Contemporary Accounting Research, v. 21, n.4, p. 843-884, 2004. http://dx.doi.org/10.1506/UDWQ-R7B1-A684-9ECR

KANG, S.; SIVARAMAKRISHNAN, K. Issues in testing earnings management and an instrumental variable approach. Journal of Accounting Research, v. 33, n. 2, p.353-367, 1995. http://dx.doi.org/10.2307/2491492

LIU, J.; UCHIDA, K.; GAO, R. Earnings management of initial public offering firms: evidence from regulation changes in China. Accounting and Finance, v. 54, p. 505-537, 2014. http://dx.doi.org/10.1111/acfi.12006

LOPES, A. B.; MARTINS, E. Teoria da contabilidade: uma nova abordagem. São Paulo: Atlas, 2010. 
; TUKAMOTO, Y. S. Contribuição ao estudo do "gerenciamento" de resultados: uma comparação entre companhias abertas brasileiras emissoras de ADR e não-emissoras de ADR. Revista de Administração Mackenzie, v. 42, n. 1, p. 86-96, 2007.

MACHADO, M. C.; NAKAO, S. H. Diferenças entre o lucro tributável e o lucro contábil das empresas brasileiras de capital aberto. Revista Universo Contábil, v. 8, n. 3, p. 100-112, 2012. DOI:10.4270/RUC.2012324

MARTINEZ, A. L. "Gerenciamento" dos resultados contábeis: estudo empírico das companhias abertas brasileiras. 2001. 167 f. Tese (Doutorado em Ciências Contábeis) Departamentos de Contabilidade e Atuária, Faculdade de Economia, Administração e Contabilidade, Universidade de São Paulo, São Paulo.

Detectando o earnings management no Brasil: estimando os accruals discricionários.

Revista Contabilidade e Finanças - USP, v. 19, n. 46, p.7-17, jan./abr. 2008.

http://dx.doi.org/10.1590/S1519-70772008000100002

NGO, A. D.; VARELA, O. Earnings smoothing and the underpricing of seasoned equity offerings. Managerial Finance, v. 38, n. 9, p.833-859, 2010.

PAE, J. Expected accrual models: the impact of operating cash flows and reversals of accruals. Review of Quantitative Finance and Accounting, v. 24, n. 1, p. 5-22, fev. 2005. http://dx.doi.org/10.1007/s11156-005-5324-7

PASTOR-LLORCA, M. J.; POVEDA-FUENTES, F. Earnings management and the long-run performance of Spanish initial public offering. In: Greg N. Gregoriou (Ed.) Initial Public Offerings: An International Perspective. Oxford: Elsevier Butterworth-Heinemann, 2005, p. 81112. Disponível em: $<$ http://papers.ssrn.com/sol3/papers.cfm?abstract_id=880766 $>$. Acesso em: 25 nov. 2013.

PAULO, E. Manipulação das informações contábeis: uma análise teórica e empírica sobre os modelos operacionais de detecção de gerenciamento de resultados. 2007. 469 f. Tese (Doutorado em Ciências Contábeis) - Departamento de Contabilidade e Atuária, Faculdade de Economia, Administração e Contabilidade, Universidade de São Paulo, São Paulo.

; CAVALCANTE, P. R. N.; MELO, I. I. S. L. Qualidade das informações contábeis na oferta pública de ações e debêntures pelas companhias abertas brasileiras. BBR - Brazilian Business Review, v. 9, n. 1, p. 1- 26, jan./mar. 2012.

; LEME, J. R. Gerenciamento de resultados contábeis e o anúncio dos resultados contábeis pelas companhias abertas brasileiras. Revista Universo Contábil, FURB, Blumenau, v. 5, n. 4, p. 27-43, out./dez. 2009. doi:10.4270/ruc.2009429

PIQUERAS, T. M. Relação das diferenças entre o lucro contábil e o lucro tributável (book-tax diferences) e gerenciamento de resultados no Brasil. 2010. 67 f. Dissertação (Mestrado) Faculdade de Economia, Administração e Contabilidade de Ribeirão Preto, Universidade de São Paulo, Ribeirão Preto.

RANGAN, S. Earnings management and the performance of seasoned equity offerings. Journal of Financial Economics, v. 50, n. 1, p. 101-122, Oct. 1998. 
RODRIGUES, L. F. Evidência de gerenciamento de resultados em oferta pública de aquisição de ações de companhias abertas: análise empírica das operações realizadas no Brasil no período de 2007 a 2012. 2013. 100 f. Dissertação (Mestrado em Ciências Contábeis) - Programa Multiinstitucional e Inter-regional de Pós-graduação em Ciências Contábeis, Universidade de Brasília, Universidade Federal da Paraíba, Universidade Federal do Rio Grande do Norte, Brasília.

ROOSENBOOM, P.; VAN DER GOOT, T.; MERTENS, G. Earnings management and initial public offerings: evidence from the Netherlands. The International Journal of Accounting, v. 38, n. 3, p. 243-266, 2003. http://dx.doi.org/10.1016/S0020-7063(03)00048-7

SANTOS, E. S. Full IFRS x lei 11.638 ( $1^{\text {a }}$ fase) x lei 6.404: impacto esperado nos resultados de 2010 a partir das empresas que se anteciparam. In: CONGRESSO USP DE CONTROLADORIA E CONTABILIDADE, 11., 2011, São Paulo. Anais... São Paulo: USP, 2011.

SANTOS, J. S. G.; PEREIRA, C. C.; LUSTOSA, P. R. B. Impacto da projeção dos analistas de mercado nos resultados das IPOs brasileiras no período de 2004 a 2009. In: CONGRESSO USP DE INICIAÇÃO CIENTÍFICA E CONTABILIDADE, 9., 2012, São Paulo. Anais... São Paulo: USP.

SCHIPPER, K. Commentary on earnings management. Accounting Horizons, v. 3, n.4, p. 91-102, 1989.

SHEN, Z.; COAKLEY, J.; INSTEFJORD, N. Earnings management and IPO anomalies in China. Review of Quantitative Finance and Accounting, v.42, n.1, p. 69-93, 2014.

http://dx.doi.org/10.1007/s11156-012-0334-8

SILVA, R. L. M. Adoção completa das IFRS no Brasil: qualidade das demonstrações contábeis e o custo de capital próprio. 2013. 219 f. Tese (Doutorado em Controladoria e Contabilidade:

Contabilidade) - Faculdade de Economia, Administração e Contabilidade, Universidade de São Paulo, São Paulo.

TEOH, S. H.; WELCH, I.; WONG, T. J. Earnings management and the long-run market performance of initial public offerings. The Journal of Finance, v. 53, n. 6, p. 1935-1974, Dec. 1998. http://dx.doi.org/10.1111/0022-1082.00079

TRUEMAN, B.; TITMAN, S. An explanation for accounting income smoothing. Journal of Accounting Research, v. 26, p. 127-139, 1988. Supplement. http://dx.doi.org/10.2307/2491184

VIEIRA, A. C. M.; OLIVEIRA, E. F. Abertura de capital das empresas no Brasil: o estudo de caso da Natura Cosméticos S. A. Revista da Pós-Gradução Unifieo, v.1, n.1, p. 1-16, 2007. Disponível em: <http://www.fieo.br/edifieo/index.php/posgraduacao/article/viewFile/50/104>. Acesso em: 25 set. 2012.

WHITE, H. A heteroskedasticity-consistent covariance matrix estimator and a direct test of heteroskedasticity. Econometrica, v. 48, n. 4, p. 817-838, 1980. http://dx.doi.org/10.2307/1912934 